\title{
DIRECTIVAS EUROPEAS SOBRE SEGURIDAD EN LA CONSTRUCCIÓN
}

\author{
(EUROPEAN DIRECTIVES ON SAFETY IN CONSTRUCTION)
}

Juan Antonio Carretero Romera, Ingeniero Técnico

Instituto Nacional de Seguridad e Higiene en el Trabajo

ESPAÑA

\section{RESUMEN}

Visión desde la óptica de un experto español de las posiciones europeas en materia de Seguridad en la Construcción, y de las Directivas Europeas y sus Transposiciones a la Legislación española.
SUMMARY

A Spanish expert's viwpoint on the European attitudes on matters of Safety in Construction and on the European Directives and their Transposition to Spanish Legislation.

\section{SEGURIDAD EN EL PRODUCTO-CALIDAD}

Vamos a tratar de la seguridad de los elementos empleados en la construcción de edificios, carreteras, etc., ya sean auxiliares o componentes de la misma -no el producto final (obra acabada) - sin dejar de dar unas pinceladas sobre política social.

Nos basaremos en lo que considero un único punto de vista posible, que es la Normativa Comunitaria (CEE) en la frontera de 1993.

Si bien todas las normativas afectan a este amplísimo campo de la construcción sólo vamos a destacar las Directivas más interesantes para nuestra actividad.

En la seguridad del producto:

- Producto de la construcción.

- Máquinas.

- Seguridad del producto.

En política social:

- La Marco.

\section{DIRECTIVA MARCO}

Con el Acta Única Europea de 1986, que entró en vigor el primero de julio de 1987, da comienzo una nueva etapa en la Comunidad Europea que, entre otros objetivos, fija el plazo para el establecimiento del Mercado Único el primero de enero de 1993. Para entonces deben estar vigentes, y en condiciones de ser aplicadas

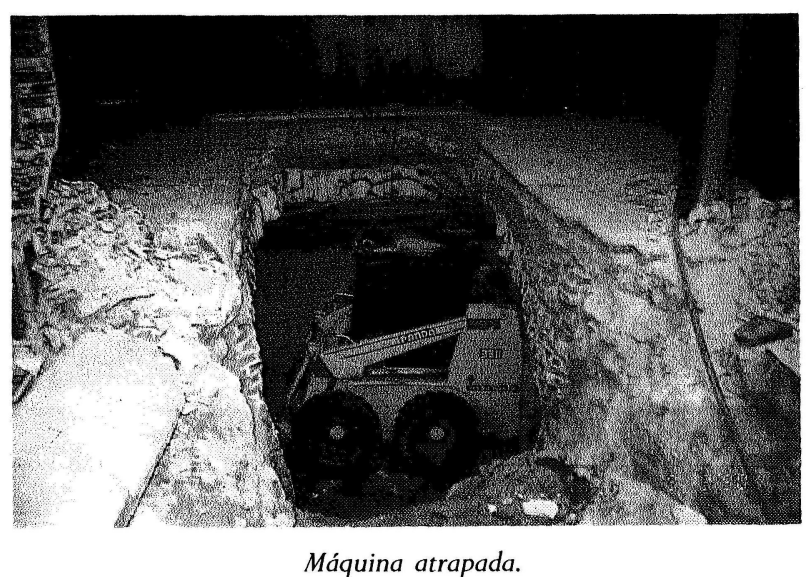


adecuadamente, un conjunto de disposiciones que regulen las condiciones de funcionamiento y desarrollo de ese Mercado. La mayoría de tales normas contienen requisitos de seguridad y de sanidad de los productos, muchas sin transponer aún a nuestra legislación.

En paralelo, pero con menos fortuna, se pretende la consolidación de un "Espacio Social Europeo", de tal manera que tal "dimensión" social de la Comunidad Europea sea tan importante como la económica en el ámbito del Mercado Único a partir de 1993.

Dentro de la Política Social de la CEE, todos los Estados aceptan el desarrollo de un Cuerpo Legal Comunitario en Materia de Seguridad y de Salud en el Trabajo, como aplicación del nuevo artículo 118-A introducido en el tratado CEE por el Acta Única.

Gracias a este "consenso" la parte básica, una Directiva Marco y al menos seis Directivas Particulares derivadas de ella -que se añaden al pequeño conjunto de disposiciones anteriores- entrarán en vigencia en el mismo plazo de primero de enero de 1993.

Tras la entrada en vigor del Acta Única, la reacción de las Instalaciones Europeas fue inmediata: la Comisión emite una Comunicación sobre su programa en el ámbito de la seguridad, la higiene y la salud en el trabajo en noviembre de 1987, que el Consejo acoge favorablemente en su Resolución de 21 de diciembre del mismo año, relativa a la seguridad, la higiene y a la salud en los lugares de trabajo. En febrero de 1988, el Parlamento Europeo aprueba cuatro resoluciones relativas a estas materias, invitando a la Comisión a que presente al Consejo propuestas de Directivas en este ámbito. En marzo de ese mismo año de 1988, a la mesa dél Consejo llega un "paquete" de seis propuestas de directivas, la Marco y cinco Particulares derivadas de ella, que se añadían a las pendientes de aprobación: la de prohibición de ciertos agentes $(88 / 364 / \mathrm{CEE})$, la modificación de la "antigua Marco" (88/642/CEE), la que más tarde se frustraría relativa al benceno y la presentada dos meses antes sobre agentes cancerígenos.

Lógicamente, la prioridad absoluta fue para la Directiva MARCO que, una vez aprobada al término de la Presidencia española el de 12 de junio de 1989, es la única directiva genérica en el ámbito de la seguridad y la salud de los trabajadores en el trabajo. La Directiva 80/1 107/CEE que hasta entonces se había considerado como "Marco", y cuyo campo de aplicación se circunscribía solamente a la Higiene en el Trabajo, debe entenderse que en este aspecto queda subordinada a la actual MARCO junto con las cuatro directivas particulares derivadas de ella, sin prejuicio de la vigencia de las disposiciones más rigurosas o específicas que contengan. A este respecto, el Consejo ha invitado a la Comisión a estudiar la coherencia de tales directivas con el Marco y a que le proponga las modificaciones correspondientes en una futura revisión de las mismas.

\section{OBJETIVOS DE LA DIRECTIVA:}

Promover la mejora de la seguridad y de la salud de los trabajadores en el marco de la empresa:

- Armonización de disposiciones mínimas.

- Responsabilidad del empresario.

- Prioridad en los principios de prevención.

- Información, participación y formación de los trabajadores.

- Organización de la acción preventiva en la empresa.

- Disposiciones de carácter general.

- Estructuración del conjunto de directivas.

\section{PRINCIPIOS GENERALES DE PREVENCIÓN:}

- Evitar riesgos.

- Evaluar los inevitables.

- Compartirlos en el origen.

- Adaptar el trabajo a la persona.

- Tener en cuenta la evolución de la técnica.

- Sustitución de lo peligroso.

- Planificación de la prevención (Integrada).

- Protección colectiva antes que individual.

- Dar instrucciones debidas a los trabajadores.

\section{ÁMBITO DE APLICACIÓN}

Las disposiciones de la Directiva se aplican a todos los casos en que exista una relación de prestaciones de servicios por cuenta ajena, con la única exclusión de los trabajadores al servicio del hogar familiar. Explícitamente se aplica a cualquier sector de actividad, tanto pública como privada, y se extiende hasta los trabajadores en prácticas y los aprendices, cualquiera que sea el tipo de contrato; se incluyen los temporales y cedidos, y el tipo de jornada. 
La Directiva, por tanto, considera como trabajador a todos los funcionarios (incluido personal estatutario) sea cual sea el sector de actividad público en el que desempeñe su trabajo, con la única excepción de aquellos casos en que las particularidades inherentes a determinadas actividades específicas se oponga de manera concluyente, tal como puede ocurrir con las fuerzas armadas o policiales, pero procurando siempre que la seguridad y la salud de estos trabajadores quede salvaguardada en la medida de lo posible.

Se aplica a todos los sectores de actividades, públicas o privadas, mencionando expresamente a título indicativo las agrícolas, industriales, comerciales, administrativas, de servicios, educativas, culturales, de ocio, etcétera.

\section{SEGURIDAD Y CALIDAD DE LOS PRODUCTOS}

Un producto utilizado y cuidado correctamente, no debe constituir un peligro para su usuario. Este principio, recogido (como derecho del usuario) en la mayoría de las legislaciones nacionales, mueve a las autoridades competentes a promulgar y vigilar el cumplimiento de reglamentos de seguridad, en los que se fijan las condiciones que deberán satisfacer los productos (potencialmente peligrosos) para poder ser comercializados y la eventual obligatoriedad de su previa homologación, es decir, de su aprobación oficial por parte de la autoridad u organismo competente, una vez realizados los exámenes o ensayos necesarios -prescritos por el propio reglamento- para comprobar que cumple los requisitos reglamentarios.

El usuario que adquiere un producto, no sólo tiene derecho a que éste no ponga en peligro su salud o seguridad, sino también a que vaya acompañado de una información sobre sus características esenciales veraz y suficiente, es decir, que le permita realmente "saber lo que compra". Por otro lado, el usuario de los países industrializados se muestra cada vez más partidario de adquirir productos "de calidad", aunque su precio sea superior al de otros productos existentes en el mercado; por supuesto, para adquirirlos debe ser capaz de reconocerlos como tales por una marca o medio de identificación que merezca su confianza.

Los grandes fabricantes o, al menos, los fabricantes que valoran su producto, desean lograr una "transparencia del mercado" que permita al usuario elegir un producto en función de su relación calidad/precio y no, exclusivamente, en base a este último factor. Por tal razón, fabricantes y usuarios están interesados en organizar un sistema para desarrollar normas sobre calidad de los productos, y para certificar que los productos que llevan una determinada marca cumplen dichas normas. La existencia de marcas de calidad de reconocimiento generalizado incide negativamente en las ventas de los productos que no la tienen.

La Administración, por su parte, promueve y apoya la organización de estos sistemas de normalización y certificación que, además de favorecer el desarrollo industrial, mejoran al mismo tiempo la seguridad de los productos. Obviamente la calidad supone, ante todo, ausencia de peligrosidad; una (buena) norma de calidad incluye siempre las oportunas especificaciones de seguridad, y un producto que se ajusta a la norma debe ser, por tanto, un producto "seguro". De hecho, y por razones que se explicitarán posteriormente, la mayoría de las normas relativas a los productos de uso industrial son normas de seguridad o, al menos, están centradas esencialmente en la temática de seguridad, aunque puedan tratar además otros temas tales como la duración del producto, su resistencia al envejecimiento, etcétera.

Obviamente, estas normas no tienen carácter vinculante y son meras recomendaciones cuya principal virtud estriba en haber sido elaboradas y aprobadas con la participación de todas las partes involucradas. Sin embargo, resulta cada vez más frecuente que los Reglamentos de Seguridad establecidos por las Autoridades competentes hagan referencia a esas Normas (o sus "partes de seguridad"); la referencia puede ser "exclusiva" o "indicativa", según el cumplimiento de la Norma sea el único, o simplemente uno de los caminos posibles para ajustarse a los requerimientos reglamentados. Paralelamente, a menudo es necesario utilizar dichas Normas como guías o criterios orientativos para la aplicación de aquellos Reglamentos cuya falta de concreción dificulte su interpretación unívoca.

De esa relación entre Reglamentos y Normas puede derivarse una relación paralela entre homologación y certificación. Supóngase que un Reglamento hace referencia a una Norma determinada (es decir, si el producto cumple la Norma, cumple, por ello, el Reglamento), y supóngase así mismo que un organismo (público o privado) certifica que el producto se ajusta a la Norma en cues- 
tión; si ese organismo satisface determinadas condiciones, la Autoridad competente puede dar a sus certificados el valor de una homologación. Mediante estos mecanismos los sistemas "compulsivos" de reglamentación y homologación $(\mathbf{R}+\mathbf{H})$, establecidos por las Autoridades competentes, pueden apoyarse y ser parcialmente sustituidos por los sistemas "voluntarios" de normalización y certificación $(\mathbf{N}+\mathbf{C})$, establecidos por libre acuerdo entre todas las partes interesadas.

\section{SEGURIDAD Y LIBRE CIRCULACIÓN}

El hecho de que un mismo producto esté sometido a distintas Reglamentaciones de seguridad, según el país donde se comercialice -y pueda tener que homologarse en cada uno de ellos- representa, sin duda, una dificultad para la libre circulación y comercialización de tales productos. Esta dificultad llega a transformarse en un impedimento prácticamente insalvable cuando sirve como escusa para las prácticas proteccionistas.

En general, los fabricantes de cualquier país -incluso los que desean un mercado libre y transparente- quieren ser protegidos de la competencia externa. La Administración suele acceder a ello para "proteger a la industria nacional" recurriendo normalmente a los aranceles, es decir, incrementando artificialmente el precio del producto. En todo caso esta forma de proteccionismo "explícito" es cada vez más difícil de realizar, al menos en el mundo desarrollado, tanto a nivel internacional (acuerdos GATT), como a nivel de la Comunidad, en la que cualquier reglamentación comercial en los Estados Miembros susceptibles de entorpecer directa o indirectamente el comercio interno se considera contraria al derecho comunitario. Sin embargo, esta regla general tiene excepciones (art. 36 del Tratado CEE): los Estados Miembros podrán establecer obstáculos a la libre circulación de productos por determinadas razones, entre las que se encuentra la protección de la seguridad y salud del usuario.

Aprovechando las posibilidades que les abría el artículo 36 del tratado CEE, los Reglamentos de Seguridad de los principales países comunitarios proliferaron y se hicieron más detallados; paralelamente aumentaron las dificultades técnicas y administrativas para la homologación de los productos importados (aunque cumplieran los reglamentos correspondientes). En definitiva, el proteccionismo enarboló la Bandera de la Seguridad, aduciendo la necesidad de proteger a las personas para justificar la protección de sus intereses comerciales.

Como resultado de la reacción de los exportadores y de la propia comisión de la CEE, frente a las citadas prácticas proteccionistas, se ha ido estableciendo una jurisprudencia comunitaria y actualmente se admite que cualquier Estado Miembro deberá aceptar en su territorio los productos legalmente comercializados o fabricados en otro, siempre que tales productos garanticen un nivel de protección o seguridad "equivalente" al exigido a los productos de fabricación y comercialización nacional. Sin embargo, nada obliga a un Estado Miembro a reconocer la equivalencia entre su reglamentación de seguridad y la de otro Estado Miembro; tales reconocimientos únicamente se han producido de forma puntual y excepcional. El principio de la seguridad equivalente sólo funciona automáticamente contra los países que carecen de tales reglamentaciones ( $\mathrm{y}$ no puede aducir, por tanto, la "no equivalencia"); es por ello que la implantación de dicho principio favoreció - contrariamente a lo deseado- el desarrollo de nuevas reglamentaciones "nacionales" de seguridad.

Adicionalmente, aun en el caso de reglamentaciones de seguridad equivalentes, el país importador es reacio a admitir las homologaciones concedidas por organismos del país exportador; aunque en ello influyan razones comerciales, no sólo debe reconocerse la equivalencia de las especificaciones de seguridad del producto, sino también la de los procedimientos de certificación y ensayo a que éste deberá someterse para evaluar su conformidad a tales especificaciones, así como la de los criterios que regulan la actuación de los organismos de certificación y ensayo.

En definitiva $-\mathrm{y}$ contra lo establecido en los Tratados Comunitarios-, alcanzar realmente un "Tratado Común" de productos (o, si se quiere, un Mercado Interior Unificado, en la terminología del Acta Única) era, a mediados de los ochenta, una meta lejana cuya consecuencia ha sido posible acelerar mediante las medidas y nuevos planteamientos.

\section{PRODUCTOS DE LA CONSTRUCCIÓN (89/106/CEE)}

El campo de aplicación de esta directiva define los productos como aquéllos de construcción destinados a ser 
incorporados, de forma permanente, a obras de construcción sujetas a normativa que contenga uno, algunos o el conjunto de requisitos esenciales desarrollados en ella (anexo I), siempre y cuando tenga relación con éstos.

Esta definición, que puede parecer ambigua por no estar perfectamente definido cada uno de los productos que contiene una construcción, considero que en la espera de algunas aclaraciones por parte de la Comisión se tome al pie de la letra para evitar sorpresas de difícil solución al no considerarse productos obligados. Es interesante la aplicación del principio que dice "Todos los productos, para su comercialización y uso, deberán ser idóneos para el uso previsto y llevar la marca CE”.

Quedan fuera de estos productos:

A. Aquéllos destinados a ser incorporados de forma provisional a las obras.

B. Aquéllos destinados, aun de forma permanente, a obras de construcción sujetas a normativa que no contenga los requisitos esenciales.

C. Aquellos que no se relacionan con ninguno de los requisitos esenciales, aun estando destinados a ser incorporados de forma permanente a obras de construcción sujetas a normativa que contenga uno, o todos los requisitos esenciales.

El único tropiezo serio que puede tener esta directiva será la ausencia, por ahora, de norma armonizada para cada uno de los productos.

Debe quedar claro que los Estados consideran idóneos para el uso aquellos productos los cuales permitan que otros, en los que sean utilizados, satisfagan los requisitos esenciales marcados en la Directiva y lleven la marca CEE.

\section{INFRACCIONES DENTRO DEL TRATADO CEE}

\section{Ámbito de aplicación:}

- Son objeto de infracción todas las disposiciones contenidas en el propio tratado CEE, y aquellos actos tales como reglamentos, decisiones, etc., tomados en virtud del tratado CEE.
- Por parte de los estados miembros existe también falta en aquellos casos en que determinados comportamientos, ya sean públicos o privados, pongan impedimentos a lo descrito en el apartado anterior.

\section{El procedimiento a seguir será según el Artículo 169 CEE:}

- El proceso se iniciará con una infracción a indicios justificados de una presunta infracción, denunciada por toda persona física o jurídica, a la Comisión Dirección General III, mediante un escrito que refleje expresamente la infracción del Estado Miembro y solicite la intervención de la Comisión.

\section{Derechos y obligaciones del demandante:}

- Se registra su queja y se le envía acuse de recibo.

- La Comisión mantiene informado al demandante de las acciones emprendidas frente a las autoridades nacionales.

- El demandante, en caso de no fructificar las medidas indicadas en el apartado anterior, es asimismo informado de la adopción de posteriores acciones, tales como el envío de la carta de emplazamiento ("mise en demeure"), del dictamen motivado ("avis motive"), recurso al Tribunal, etcétera.

- El demandante puede, en todo momento, consultar los servicios de la comisión a fin de conocer la situación del expediente.

- El demandante tiene derecho a la gratuidad en la instrucción del expediente.

No se exige, por otra parte, ninguna obligación formal al demandante, tan sólo el deber moral de colaborar con los servicios de la Comisión para facilitar la instrucción del expediente, especialmente cuando se trata de verificar y responder a las observaciones transmitidas por el Estado Miembro encausado. 